\title{
Article \\ Establishment of a Novel In Vitro Model of Endometriosis with Oncogenic KRAS and PIK3CA Mutations for Understanding the Underlying Biology and Molecular Pathogenesis
}

\author{
Mohammad Mahmud Hossain ${ }^{1}$, Kentaro Nakayama ${ }^{1, *}$, Kamrunnahar Shanta ${ }^{1} \mathbb{D}$, Sultana Razia ${ }^{1}$, \\ Masako Ishikawa ${ }^{1}$, Tomoka Ishibashi ${ }^{1}$, Hitomi Yamashita ${ }^{1}$, Seiya Sato ${ }^{1}$, Kouji Iida ${ }^{1}$, Kosuke Kanno ${ }^{1}$, \\ Noriyoshi Ishikawa ${ }^{2}$, Tohru Kiyono ${ }^{3, *}$ and Satoru Kyo ${ }^{1}$
}

check for updates

Citation: Hossain, M.M.; Nakayama, K.; Shanta, K.; Razia, S.; Ishikawa, M.; Ishibashi, T.; Yamashita, H.; Sato, S.; Iida, K.; Kanno, K.; et al. Establishment of a Novel In Vitro

Model of Endometriosis with Oncogenic KRAS and PIK3CA Mutations for Understanding the Underlying Biology and Molecular Pathogenesis. Cancers 2021, 13, 3174. https://doi.org/10.3390/

cancers13133174

Academic Editor: Ruud L. M. Bekkers

Received: 8 April 2021

Accepted: 22 June 2021

Published: 25 June 2021

Publisher's Note: MDPI stays neutral with regard to jurisdictional claims in published maps and institutional affiliations.

Copyright: (c) 2021 by the authors. Licensee MDPI, Basel, Switzerland. This article is an open access article distributed under the terms and conditions of the Creative Commons Attribution (CC BY) license (https:// creativecommons.org/licenses/by/ $4.0 /)$.
1 Department of Obstetrics and Gynecology, Shimane University Faculty of Medicine, Izumo 693-8501, Japan; likhon.vet@gmail.com (M.M.H.); kamrunnahar.vet@gmail.com (K.S.); raeedahmed@yahoo.com (S.R.); m-ishi@med.shimane-u.ac.jp (M.I.); tomoka@med.shimane-u.ac.jp (T.I.); meme1103@med.shimane-u.ac.jp (H.Y.); sseiya@med.shimane-u.ac.jp (S.S.); iida@med.shimane-u.ac.jp (K.I.); kanno39@med.shimane-u.ac.jp (K.K.); satoruky@med.shimane-u.ac.jp (S.K.)

2 Department of Organ Pathology, Shimane University Faculty of Medicine, Izumo 693-8501, Japan; kanatomo@med.shimane-u.ac.jp

3 Project for Prevention of HPV-Related Cancer, Exploratory Oncology Research and Clinical Trial Center (EPOC), National Cancer Center, Kashiwa 277-8577, Japan

* Correspondence: kn88@med.shimane-u.ac.jp (K.N.); tkiyono@east.ncc.go.jp (T.K.)

Simple Summary: Endometriosis is a common gynecological condition that causes pelvic pain and infertility. Despite having normal histological features, several cells bear cancer-associated somatic mutations that result in local tissue invasion but rarely metastasize. Several cancer-associated genes, such as KRAS and PIK3CA, are frequently mutated in the endometriotic epithelium. However, the functional behavior and molecular pathogenesis of this disorder remain unclear. In this study, we developed an immortalized endometriotic epithelial cell line with mutations in KRAS and PIK3CA, which are genes associated with aggressive behaviors, such as increased cell migration, invasion, and proliferation. Through microarray analysis, the KRAS- and PIK3CA-specific gene signatures were identified; LOX and PTX3 were found to be responsible for this metastatic behavior. Knockdown of these two genes by siRNA markedly reduced the metastatic ability of the cells. Our findings suggest that inhibition of LOX and PTX3 may be an alternative therapeutic strategy to reduce the incidence of endometriosis.

Abstract: Endometriosis-harboring cancer-associated somatic mutations of PIK3CA and KRAS provides new opportunities for studying the multistep processes responsible for the functional and molecular changes in this disease. We aimed to establish a novel in vitro endometriosis model to clarify the functional behavior and molecular pathogenesis of this disorder. Immortalized HMOsisEC10 human ovarian endometriotic epithelial cell line was used in which KRAS and PIK3CA mutations were introduced. Migration, invasion, proliferation, and microarray analyses were performed using KRAS and PIK3CA mutant cell lines. In vitro assays showed that migration, invasion, and proliferation were significantly increased in KRAS and PIK3CA mutant cell lines, indicating that these mutations played causative roles in the aggressive behavior of endometriosis. Microarray analysis identified a cluster of gene signatures; among them, two significantly upregulated cancer-related genes, lysyl oxidase (LOX) and pentraxin3 (PTX3), were associated with cell proliferation, invasion, and migration capabilities. Furthermore, siRNA knockdown of the two genes markedly reduced the metastatic ability of the cells. These results suggest that endometriosis with KRAS or PIK3CA mutations can significantly enhance cell migration, invasion, and proliferation by upregulating $L O X$ and PTX3. We propose that LOX and PTX3 silencing using small molecules could be an alternative therapeutic regimen for severe endometriosis. 
Keywords: ovarian endometriosis; epithelial cell line; PIK3CA; KRAS; invasion; migration; cell proliferation; microarray analysis; LOX; PTX3

\section{Introduction}

Endometriosis is a benign inflammatory disease, characterized with the recurrent estrogen-dependent ectopic growth of the endometriotic epithelium and stroma outside the uterus. It affects approximately $10-15 \%$ of the women of reproductive age [1,2], causing pelvic pain and infertility [2,3]. Despite its low mortality rate, endometriosis has a significant impact on the quality of life and work productivity and is a substantial socioeconomic burden on the healthcare system $[4,5]$. Endometriosis has been clinically recognized for more than a century, but its pathogenesis and mechanism of dissemination remain unclear. The current prevailing hypothesis is that endometriosis results from retrograde menstruation, causing the endometriotic cells (composed of epithelial glands and stromal cells) to adhere to the pelvic peritoneum, ovaries, and rectovaginal septum, with subsequent implantation and proliferation until they form endometriotic lesions [6,7]. Anatomically, endometriosis has three major manifestations in the pelvic region: superficial, ovarian, and deep infiltrating [8,9]. Although it was previously considered a benign condition with normal-acting histological features, recent studies have established that endometriosis can recapitulate some cancer-like features, such as cell proliferation, migration, and invasion. Furthermore, one study showed that recurrently mutated cancer driver genes, such as KRAS, PIK3CA, PPP2R1A, and ARID1A, are also present in endometriosis without cancer association [3]. Consequently, ovarian endometriosis may be considered a precursor of endometrioid ovarian carcinoma and clear cell carcinoma [10-13]. In addition, some studies have suggested that mucinous metaplasia in ovarian endometriosis could be closely linked to the development of borderline mucinous ovarian carcinoma with KRAS mutation, which may eventually progress to invasive carcinoma [14,15]. Recently, some studies have revealed that ovarian endometriosis, deep-infiltrating endometriosis, uterine adenomyosis, and normal uterine endometrium harbored cancer-associated somatic mutations [3,16-21]. Additionally, PIK3CA or KRAS mutated clones arising in the histologically normal uterine endometrium have been proposed as the cellular origins of endometriosis [3]. The transformation of a normal cell into a cancer cell is caused by the acquisition of driver mutations and epigenetic modifications, accompanied by changes in the cellular morphology and tissue architecture [22]. However, no behavioral and functional analysis of the aforementioned genes in endometriosis has been performed.

In the current study, we aimed to comprehensively analyze the roles of KRAS and PIK3CA oncogenes in endometriosis. To this end, we established an immortalized cell line model from ovarian endometriotic epithelial cells to perform in vitro cellular functional analyses (migration, invasion, and proliferation assays). In addition, we performed microarray analyses of immortalized endometriotic epithelial cell lines (KRAS and PIK3CA mutant) to identify migration and invasion-related gene signatures. To the best of our knowledge, this is the first study to perform a functional analysis of KRAS and PIK3CA mutant endometriotic epithelial cells.

\section{Results}

\subsection{Development of Immortalized Epithelial Cell Lines from Ovarian Endometriotic Tissue}

Surface epithelial tissue of ovarian endometriosis was collected from a 48-year-old patient undergoing laparoscopic ovarian cystectomy as treatment for ovarian endometriosis. To determine whether mixing of malignant and our collected sample had occurred, we conducted further pathological examination and found no malignant lesions. In a previous study, it was found that the triple expression of an active CDK4 mutant (CDK4 $\left.{ }^{\mathrm{R} 24 \mathrm{G}}\right)$, cyclin D1, and hTERT were sufficient to immortalize epithelial cells [23]. Based on this, we also introduced these factors into our isolated endometriotic cells and observed their 
morphology. We noted the absence of morphological changes in the immortalized ovarian endometriotic epithelial cells, along with faster growth and overcoming of premature senescence. We named these cell lines HMOsisEC10 (Wild type), HMOsisEC10 KRAS mutant and HMOsisEC10 PIK3CA mutant cell lines (Figure S1).

\subsection{Western Blot Analysis of pan-Cytokeratin, pan-AKT, pan-MAPK, $p-M A P K$, and $p-A K T$ Expression in Immortalized Cells}

To confirm the epithelial origin of the immortal endometriotic cells, Western blotting and immunocytochemistry using pan-cytokeratin were performed. The results showed that the epithelial morphology was highly detectable in the HMOsisEC10 immortal cell line (Figure S2). We subsequently focused on the status of the KRAS and PIK3CA mutations. Western blot assays showed that the RAS/ERK signaling pathway was strongly activated in the HMOsisEC10 KRAS mutant cells, whereas the PI3K/AKT signaling pathway was activated in the HMOsisEC10 PIK3CA mutant cells (Table S1 and Figure S3).

\subsection{Short Tandem Repeat (STR) Analysis}

Maintaining genetic stability in continuously cultured cells is critical for life science research. We performed STR analysis to evaluate the integrity (genetic origin and crosscontamination) of the immortalized HMOsisEC10 cell line. Specifically, we tested DNA samples from HMOsisEC10 early and late passages 2, 13, and 22. Eight STR loci (TPOX, CSF1P0, VWA, FGA, D3S1359, D18S51, D8S315, and SE33) per sample were amplified. We observed that cells from all three passages had identical STR profiling patterns in the eight loci (Figure S4). This result suggests that cross-contamination was absent across these cell lines.

\subsection{Migration, Invasion, Proliferation, and Anchorage-Independent Assays of Mutant Cells}

To check the cellular functional behavior, we conducted an in vitro migration assay by using the immortalized cell lines we established. The results showed that the HMOsisEC10 KRAS and HMOsisEC10 PIK3CA mutant cell lines had significantly higher migration ability than the HMOsisEC10 cell line (Figure 1A,B). We next examined the invasion behavior of the cells using the Matrigel invasion assay. In this assay, cells are required to invade the extracellular matrix barrier. FBS (20\%) was used as a chemoattractant, and cell invasion was assessed after $24 \mathrm{~h}$. The HMOsisEC10 KRAS and HMOsisEC10 PIK3CA mutant cell lines demonstrated significantly increased invasion ability compared to the HMOsisEC10 cell line (Figure 1C,D). The cellular proliferation assay revealed a similar result, where HMOsisEC10 KRAS and HMOsisEC10 PIK3CA mutant cells exhibited significantly increased proliferation compared to HMOsisEC10 (Figure 1E). To evaluate the transformation phenotype, an anchorage-independent assay was performed, which showed no colonies in either the HMOsisEC10 KRAS or HMOsisEC10 PIK3CA mutant cell lines. SKOV3 was simultaneously examined as a positive control where several distinct colonies were identified (Figure S5).

\subsection{Constitutive Effect of Tumorigenicity in HMOsisEC10 KRAS and HMOsisEC10 PIK3CA Mutant Cells}

Having established the phenotypic changes in the HMOsisEC10 KRAS and HMOsisEC10 PIK3CA mutant epithelial cell lines, we next examined whether these cells showed altered tumor growth in nude mice. Subcutaneous injections of HMOsisEC10 KRAS and HMOsisEC10 PIK3CA mutant cells in nude mice did not produce any forms of tumor within two months of monitoring. Besides, SKOV3 cells were inoculated as positive control and exhibit tumor (Figure S6). 
A
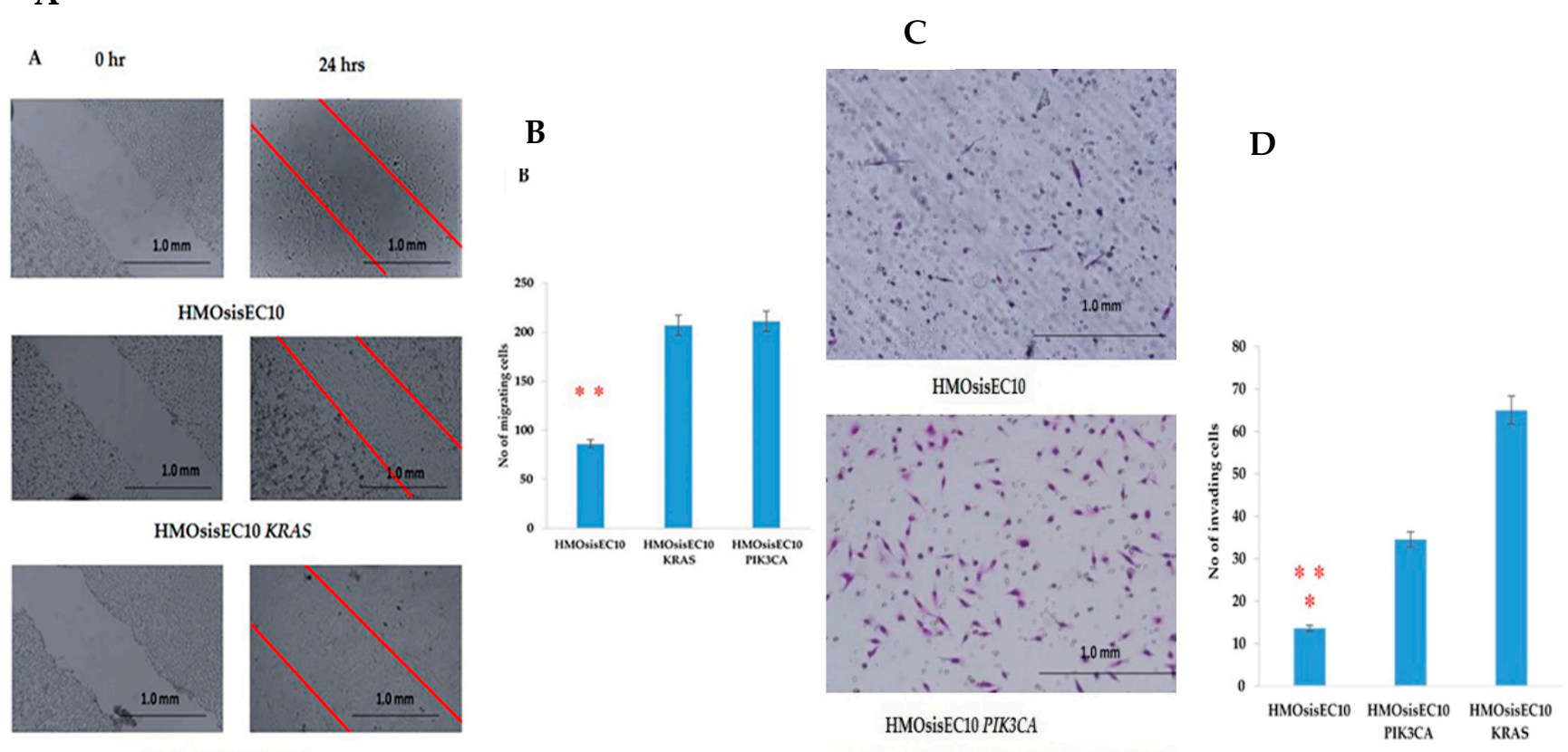

HMOSisEC10 PIK3CA

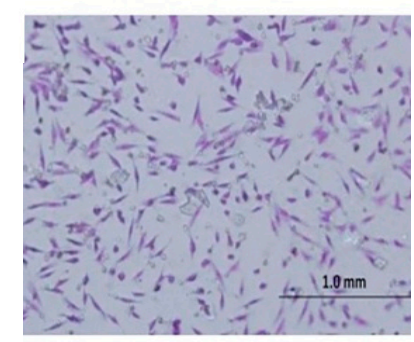

HMOSisEC10 KRAS

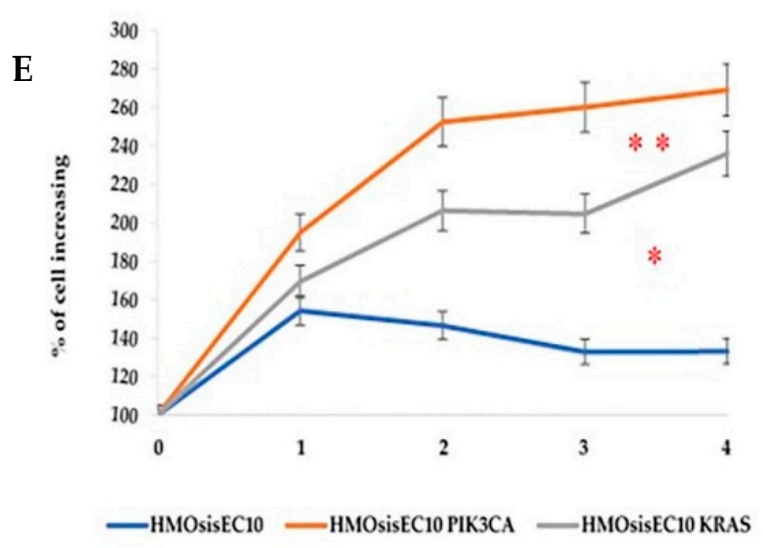

Figure 1. HMOsisEC10 KRAS and HMOsisEC10 PIK3CA cells exhibit increased migration, invasion, and proliferation relative to HMOsisEC10 cells. Cell migration assay (A,B). HMOsisEC10 KRAS and HMOsisEC10 PIK3CA cell lines show increased cell migration in the wound healing assay. Photographs captured immediately after the scratch $(0 \mathrm{~h}$, upper left panel) and $24 \mathrm{~h}$ post-scratch (upper right panel). The number of migrated cells is significantly higher in the HMOsisEC10 KRAS and HMOsisEC10 PIK3CA mutant cell lines than in the HMOsisEC10 cell line $(* * p<0.05)$. Matrigel invasion assay (C,D). The HMOsisEC10 KRAS and HMOsisEC10 PIK3CA mutant cell lines demonstrate a significantly higher invasion capacity than the control HMOsisEC10 cell line ${ }^{* *} p<0.01$ and ${ }^{*} p<0.05$, respectively). Cell proliferation assay (E). The proliferation capability of the mutant HMOsisEC10 KRAS and HMOsisEC10 PIK3CA cell lines are significantly higher than that of the HMOsisEC10 cell line ${ }^{*} p<0.05$ and ${ }^{* *} p<0.01$, respectively). The error bars indicate standard deviation. 


\subsection{Lack of Other Genetic Mutations in Immortalized Epithelial Cells}

We next performed the whole-exome sequencing to identify whether the immortal HMOsisEC10 cell line had acquired any tumor-specific somatic mutations. We evaluated the mutation burden of 728 cancer-related genes and the genomic DNA analysis results were compared with the result from normal endometriotic tissue. The result revels that there were no cancer specific alterations in somatic genes, including single-nucleotide variations, insertions, or deletions. The results also found no copy number alterations in oncogenes, or deficiencies in mismatch repair genes, homologous recombination genes, and tumor suppressor genes (Table S2 and Figure S7).

\subsection{Identification and Analysis of Genes Involved in Cell Migration, Invasion, and Proliferation}

We performed microarray analysis with the aim of identifying the genes that are responsible for migration, invasion, and proliferation in HMOsisEC10 KRAS and HMOsisEC10 PIK3CA mutant cell lines. Microarray analysis revealed 5959 genes that displayed changes in the pattern of gene expression, such as increased or decreased expression in the three different cell lines. Among them, eight genes were found to be more than two-fold over-expressed, and 24 genes were under-expressed in both the HMOsisEC10 KRAS and HMOsisEC10 PIK3CA cell lines compared to the HMOsisEC10 cells in genes associated with migration (Figure 2A). With regard to invasion, heat map analysis revealed that 7 genes were more than two-fold over-expressed, whereas 18 genes were under-expressed in KRAS and PIK3CA mutant cells (Figure 2B). From this gene list, gene expression changes associated with migration and invasion potential were identified by conducting a comprehensive search using the PubMed database. Owing to their high migration and invasion ability, the LOX and PTX3 genes were selected for further analysis from the top upregulated genes. Microarray analysis was also helpful to identify the pathways regulated in endometriosis in the HMOsisEC10 KRAS and HMOsisEC10 PIK3CA mutant cells.

\subsection{Validation of Microarray Data by Reverse Transcriptase Polymerase Chain Reaction (RT-PCR)}

To confirm the differential expression of the genes identified by cDNA microarray analysis of mRNA samples isolated from the KRAS and PIK3CA mutant cell lines, we analyzed two upregulated genes using RT-PCR. GAPDH expression was used as a control for the input cDNA. The RT-PCR results were consistent with those obtained from the microarray analysis, indicating that the microarray results provided an accurate report of the transcript levels (Figure S8).

\subsection{Signaling Pathways Targeting KRAS and PIK3CA Mutations in Endometriosis Due to the Upregulation of Lysyl Oxidase (LOX) and Pentraxin3 (PTX3)}

In order to recognize the pathways (Figure 3 ) that were regulated in endometriosis, a global microarray analysis was undertaken. Through this analysis, we recognized a cluster of genes and the associated pathways that automatically promoted cell proliferation, invasion, and migration in endometriotic epithelial cells by regulating mutant KRAS and PIK3CA expression. These genes included LOX and PTX3. Apart from these two genes, several principle regulators were present in this system, such as transcription factors, cell adhesion molecules, and microRNAs that may interact and stimulate the expression of these and several other genes. A previous report suggested that KRAS and PIK3CA mutations have a synergistic effect in activating the PI3K-AKT-mTOR pathway [24], and KRAS mutations activate the RAS and RAF proteins, which have the capability to regulate several signaling cascades important for cell proliferation, migration, and invasion [25], including the MAPK/ERK pathway. Notably, the PI3K-AKT-mTOR pathway and RAS/RAF/MAPK/ERK pathway have similar up regulation effects on RhoA activity (a Rho GTPase that acts as oncogene) [26]. The microarray data obtained in this study revealed upregulation of RhoA, TNF- $\alpha$, and serum response factor (SRF) expression in KRAS and PIK3CA mutant cell lines (Table S3). The overexpressed RhoA stimulates cell cycle progression as well as enhances cell migration through activation of TNF- $\alpha[27,28]$. 
The transcriptional factor SRF is activated by the influence of Rho subfamily [29], and upregulated LOX and PTX3 might have positive effects on cell proliferation, migration, and invasion potential.

A

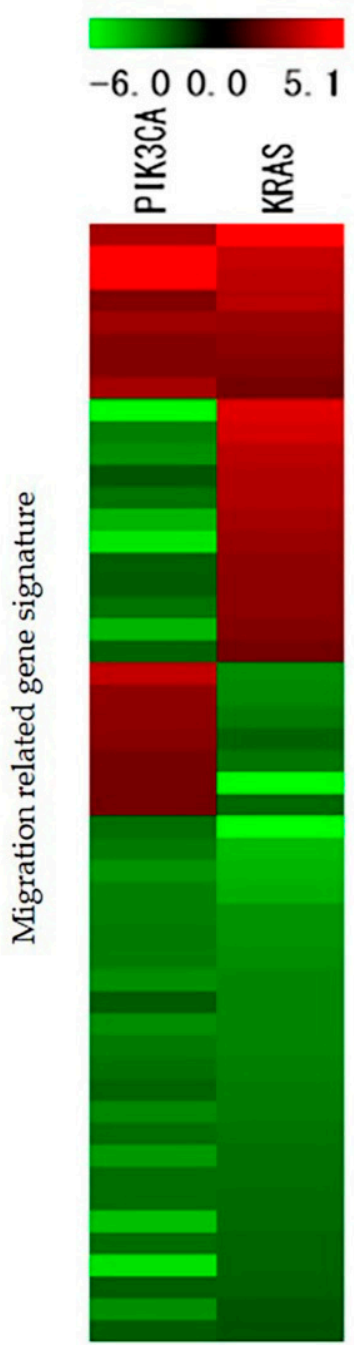

B

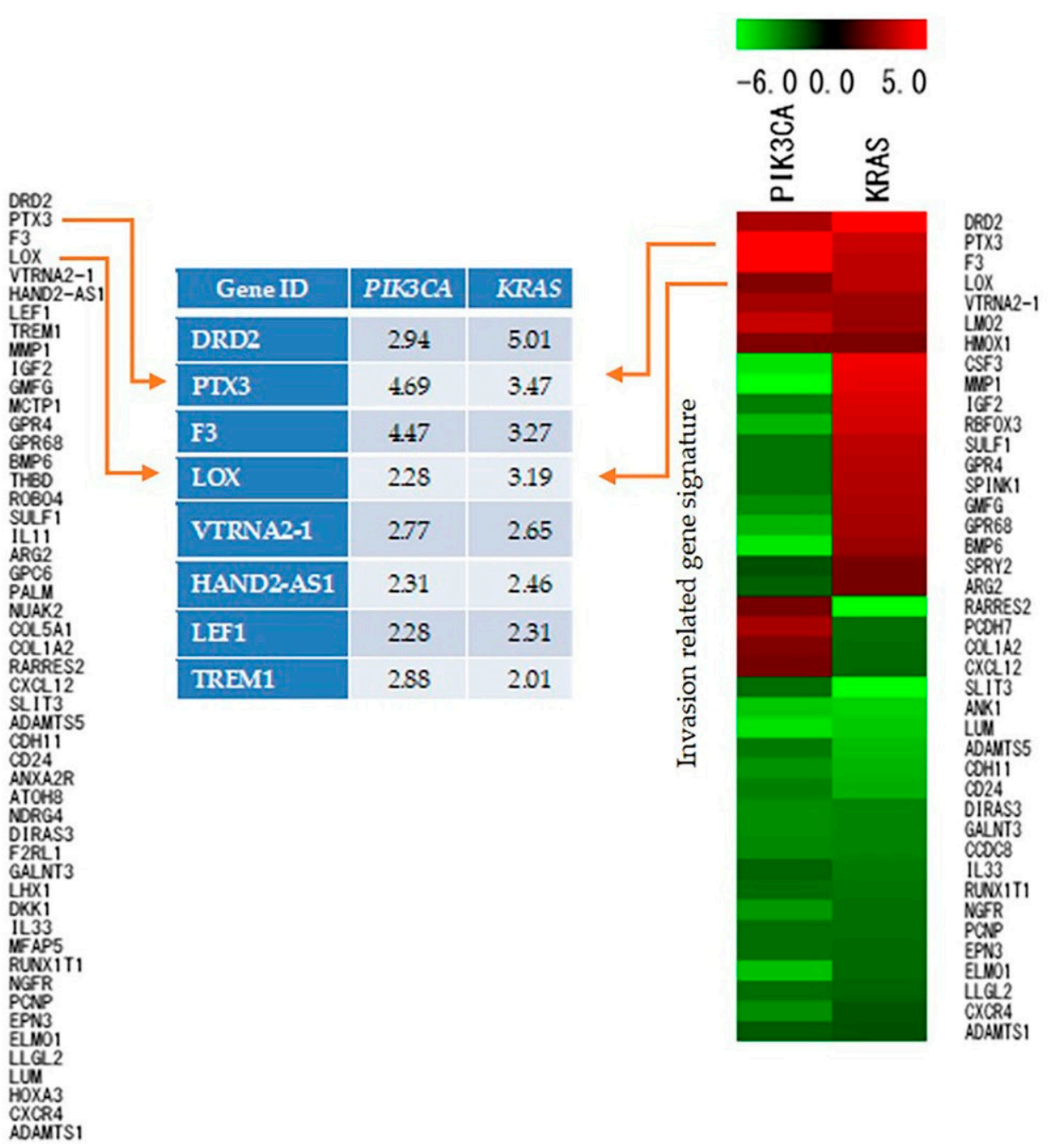

Figure 2. Gene expression analysis. Heat map representing expression pattern for migration (A) and invasion (B)-related gene signatures in the HMOsisEC10 KRAS and HMOsisEC10 PIK3CA mutant cell lines. Red color shows upregulated genes, and green color shows downregulated genes. Arrowhead indicates the genes selected for further analysis.

2.10. LOX and PTX3 mRNA Expression Levels Are Upregulated in Immortalized Endometriotic Mutant Epithelial Cells

First, we determined the mRNA levels of LOX and PTX3 in immortalized endometriotic epithelial cells using RT-PCR. Our results revealed the mRNA levels of LOX and PTX3 in cells expressed as relative units after normalization with the housekeeping gene GAPDH. LOX and PTX3 were highly expressed in the mutant cell lines (HMOsisEC10 KRAS and HMOsisEC10 PIK3CA) compared to the wild-type HMOsisEC10 cell line (Figure 4). 


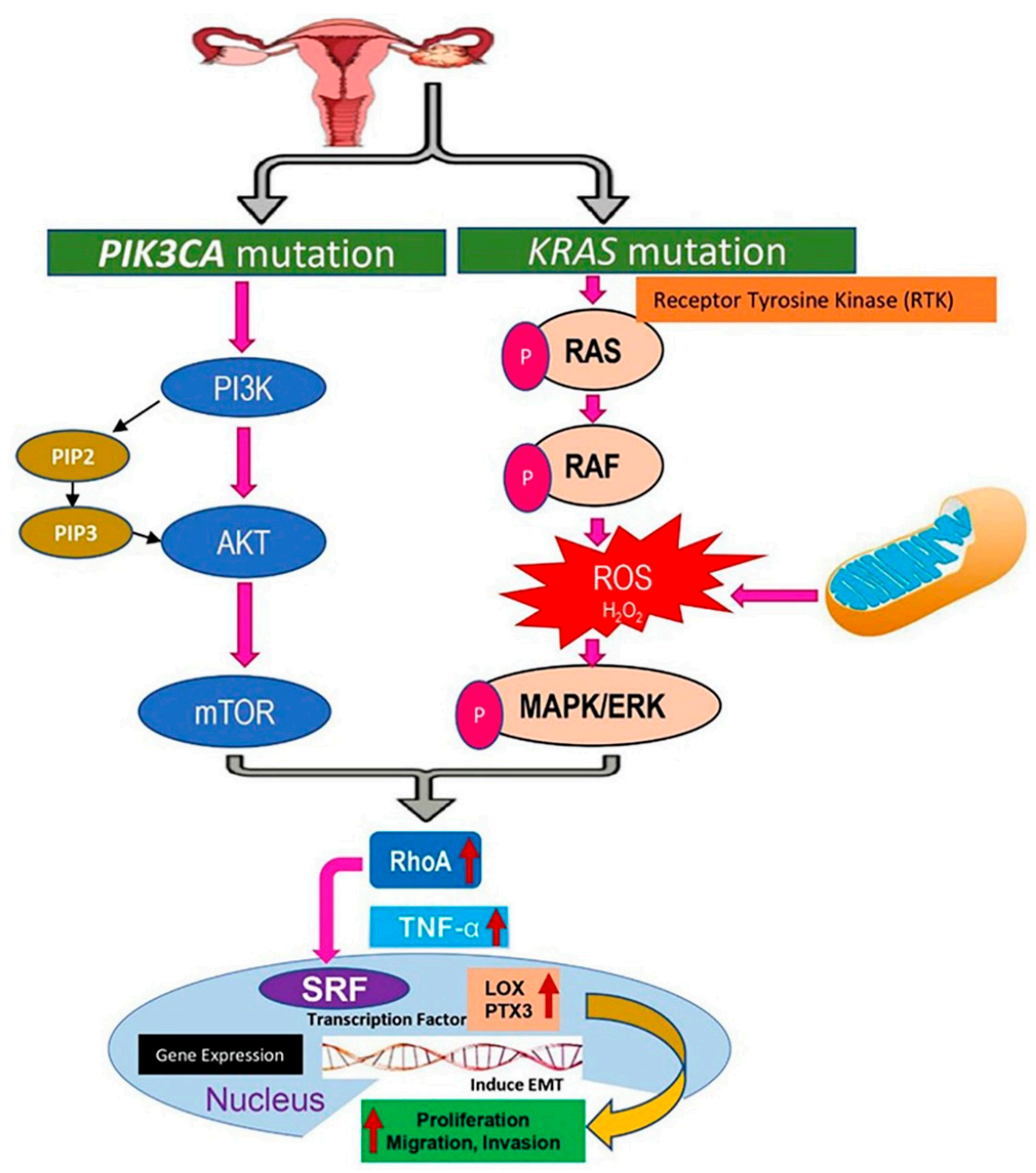

Figure 3. Targeting KRAS and PIK3CA mutations in endometriosis; KRAS mutation activates RAS, RAF, and MAPK/ERK with the aid of receptor tyrosine kinases through phosphorylation. PI3K is activated by the PIK3CA mutation, which results in phosphorylation of PIP2 to PIP3 and activates AKT and mTOR. MAPK/ERK and mTOR have common effects on RhoA activity, which regulates the serum response elements (SRF) with the help of TNF- $\alpha$. SRF is a transcription factor that has downstream effects on LOX and PTX3 leading to cell proliferation, migration, and invasion.
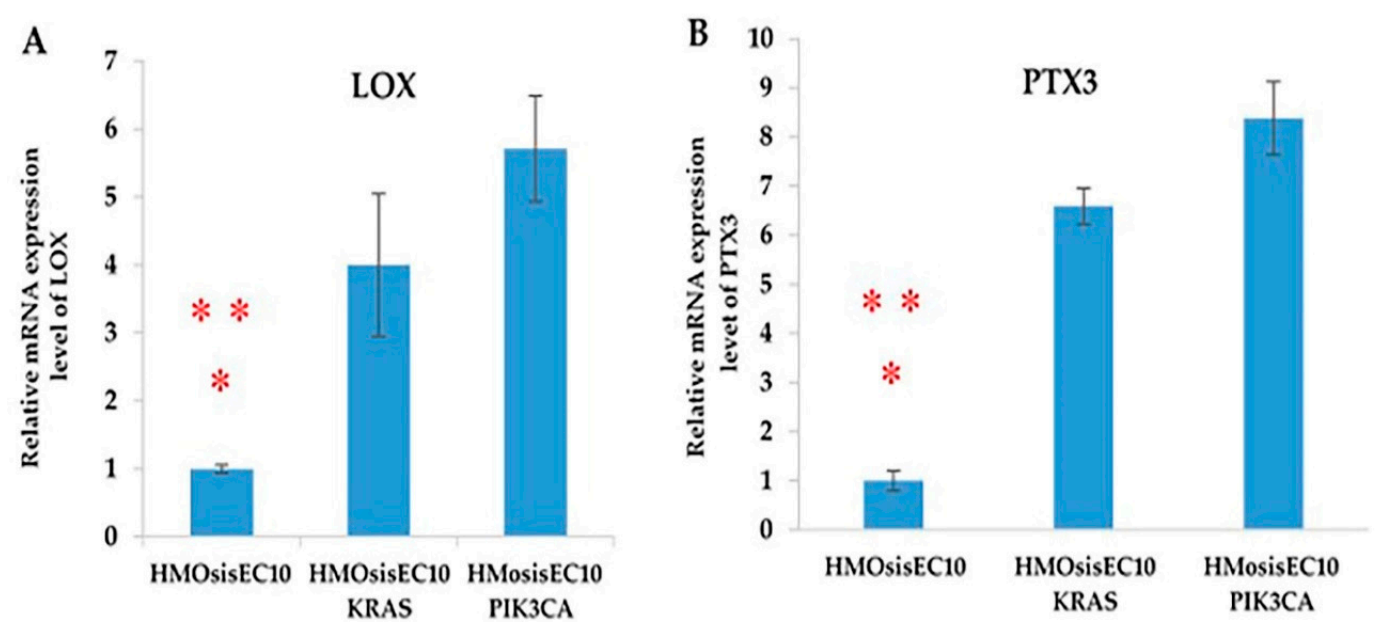

Figure 4. mRNA expression levels of LOX (A) and PTX3 (B) are evaluated in mutant cell lines (HMOsisEC10 KRAS and HMOsisEC10 PIK3CA). RT-PCR results revealed that both mutant cell lines showed a significantly higher expression of LOX and PTX3 compared to the HMOsisEC10 cell line $\left({ }^{*} p<0.05\right.$ and $\left.{ }^{* *} p<0.01\right)$. Error bars indicate standard deviation. 
2.11. Constitutive Knockdown of LOX and PTX3 Leads to Decreased Migration, Invasion, and Proliferation in KRAS and PIK3CA Mutant Cell Lines

To confirm that the overexpression of LOX and PTX3 led to an increase in the migration, invasion, and proliferation ability in the KRAS and PIK3CA mutant cell lines, we applied a complementary approach using a gene knockdown system. HMOsisEC10 KRAS and HMOsisEC10 PIK3CA cells were transfected with siRNA (Santa Cruz Biotechnology) against $L O X$ and $P T X 3$, and the effect on cell migration was measured by using a wound healing assay after $48 \mathrm{~h}$. Our data showed that siRNA knockdown of both LOX and PTX3 significantly inhibited cell migration (Figure 5A1,2,B1,B2). We also examined whether the silencing of these genes could affect cellular invasion. Both LOX and PTX3 significantly inhibited mutant cell invasion (Figure 5C1,C2,D1,D2). Similarly, we conducted a cell proliferation assay after silencing of LOX and PTX3 for $48 \mathrm{~h}$ and found that cell proliferation was significantly reduced (Figure 5E1,E2,F1,F2). Other LOX and PTX3 siRNAs (Ambion Life Technologies) were also tested using migration, invasion, and proliferation assays (Figure S9); siRNA sequences are listed in Table S4.

A1

HMOsisEC10 KRAS

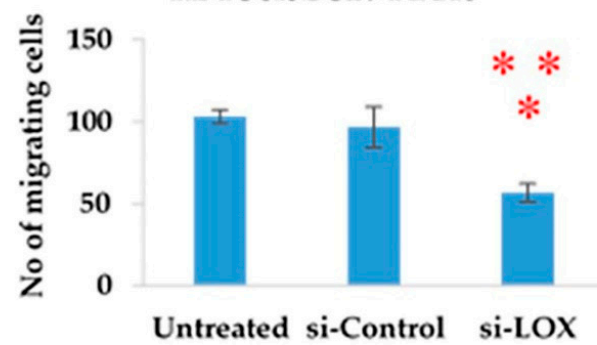

B1

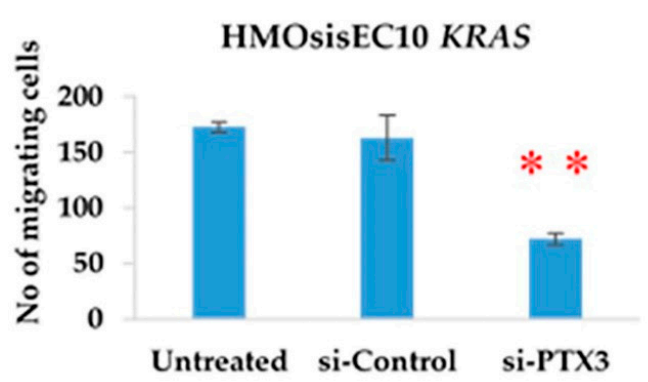

C1

HMOsisEC10 KRAS

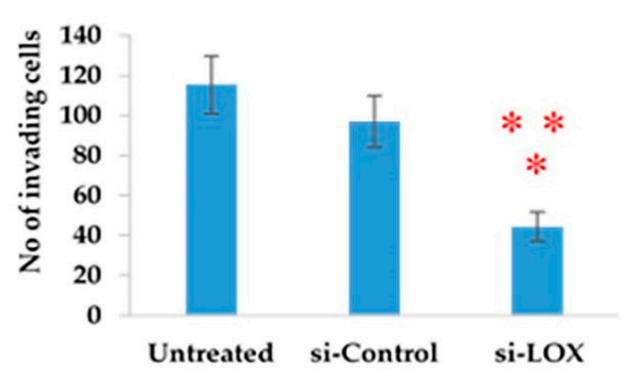

A2

HMOsisEC10 PIK3CA

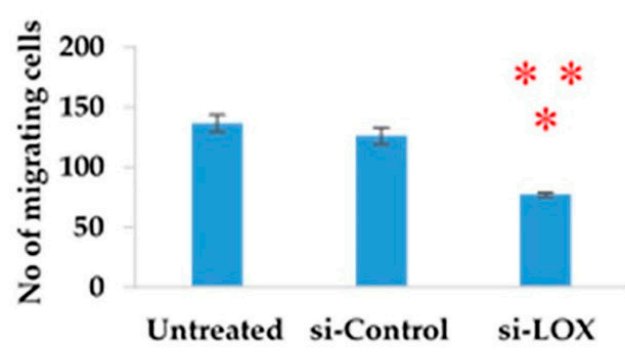

B2

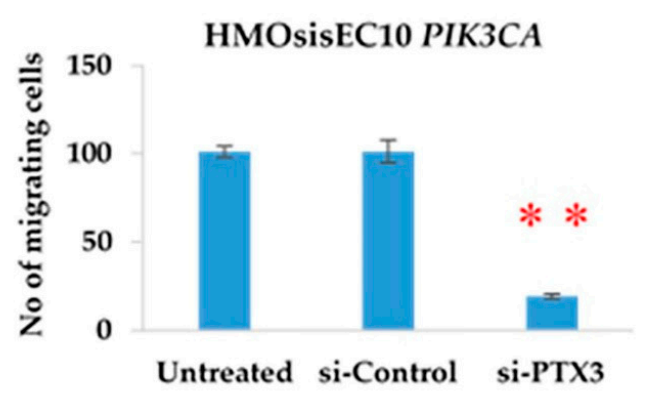

C2

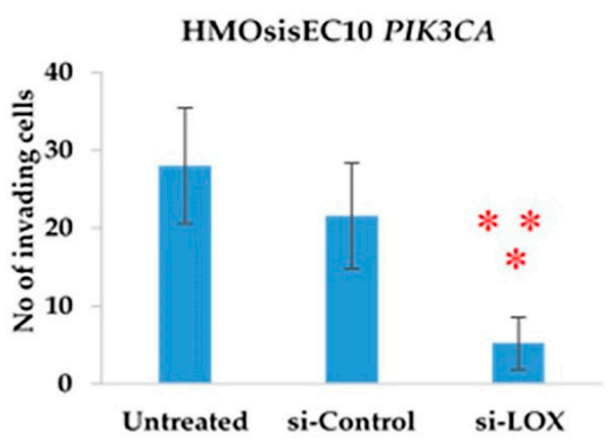

Figure 5. Cont. 
D1

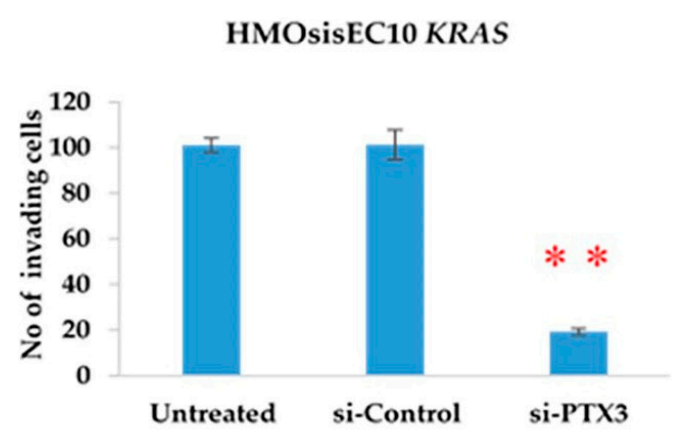

E1

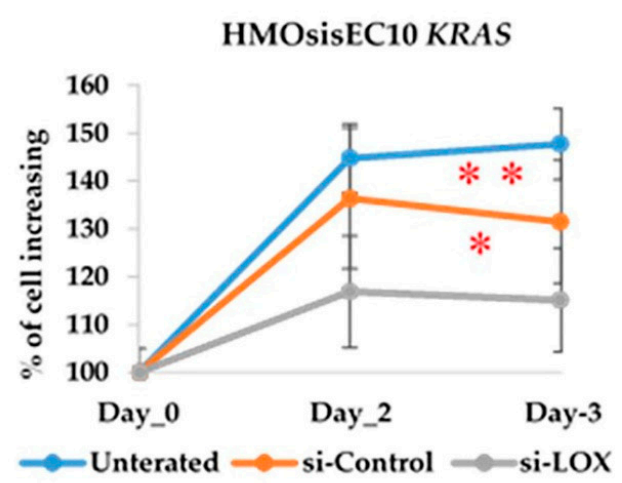

F1

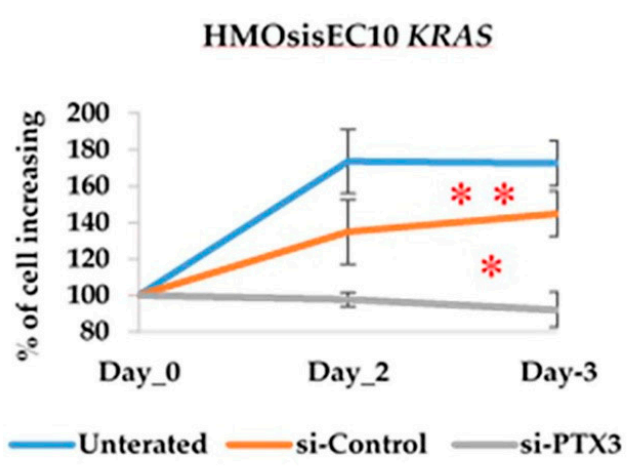

D2

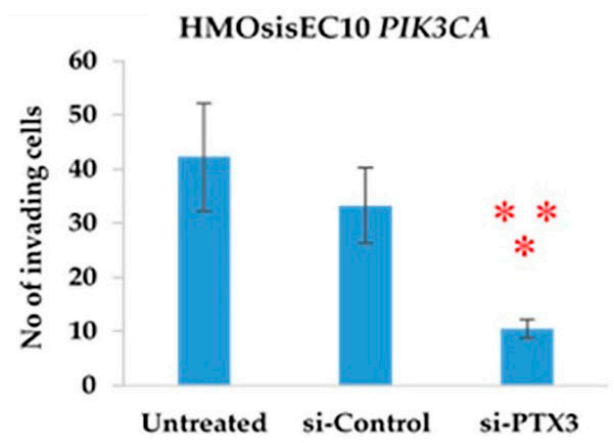

E2

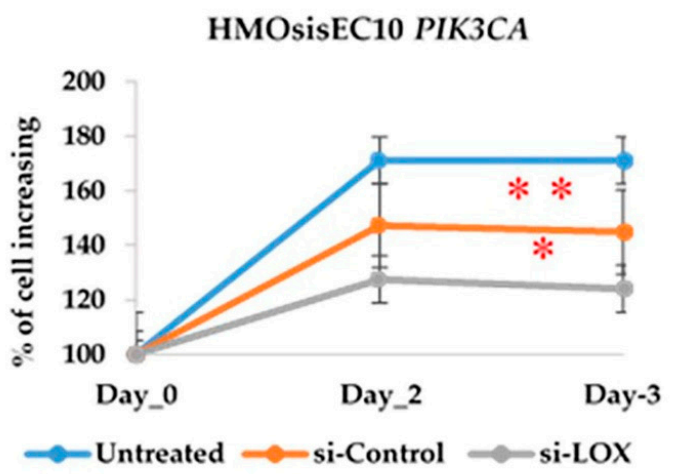

F2

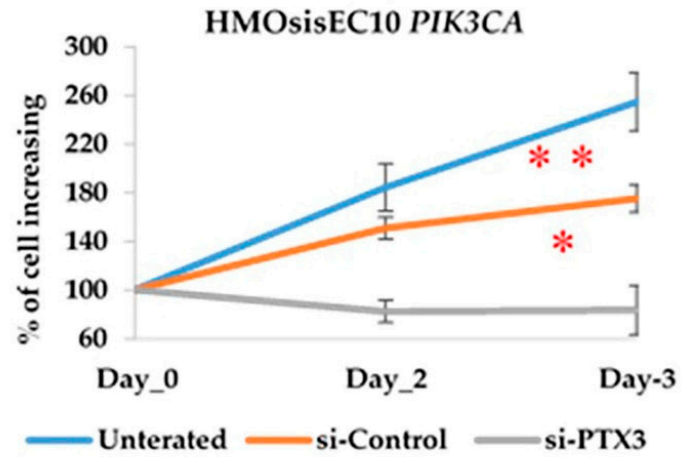

Figure 5. Cell migration assay. Migration abilities of mutant cell lines (HMOsisEC10 KRAS and HMOsisEC10 PIK3CA) are measured using a scratch wound healing assay after knockdown with LOX (A1,A2) and PTX3 siRNA (B1,B2). The numbers of migrated cells were significantly lower in siRNA treated cells compared to the control siRNA and untreated cells. Matrigel Invasion assay. siRNA knockdown of LOX $(\mathbf{C} 1, \mathbf{C} 2)$ and PTX3 (D1,D2) showed a significantly lower invasion capacity than control siRNA and untreated cells. Cell proliferation assay. Treatment with LOX (E1,E2) and PTX3 siRNA $(\mathbf{F 1}, \mathbf{F} 2)$ significantly reduced cell proliferation ability relative to the control siRNA and untreated cells. ${ }^{* *} p<0.01$ and ${ }^{*} p<0.05$. The error bars indicate standard deviation.

\section{Discussion}

Despite the high prevalence of endometriosis and its outcome on women's health, very little is known about the biological processes that reinforce it, although more than an era has passed since this disease was first described [3,5]. Anglesio et al. reported that $26 \%$ of patients with deep-infiltrating endometriotic epithelial cells showed somatic cancer driver mutations, such as KRAS, PIK3CA, PPP2RIA, and ARID1A [3]. Moreover, 
ovarian endometriotic cysts and uterine endometrium also harbored cancer-associated somatic mutations [16,17]. Furthermore, KRAS mutations in different tissue areas have been reported, suggesting the presence of clonal heterogeneity and that a gradual process of changes in endometriosis is possible [3]. Among the targeted genes, KRAS and PIK3CA are most frequently mutated in the normal epithelial cells of the uterine endometrium and in endometriosis, with a higher mutant allele frequency (MAF). This increasing MAF in cancerassociated genes in the endometriotic epithelium recommend cancer-associated mutation already harboring in retrograde flow of endometrial cells before implantation/seeding, or they may independently arise in the implanted endometriotic epithelial cells thereby inducing the development of endometriosis [3,16-21]. Accordingly, our study aimed to investigate the functional behavior of these KRAS and PIK3CA cancer-driver genes along with identifying the somatic mutations associated with the aggressive benign tumor in the developed immortalized endometriotic epithelial cell line, HMOsisEC10. In addition, using microarray analysis, we also identified the overexpression of LOX and PTX3 in KARS and PIK3CA mutant cell lines compared to the HMOsisEC10 cells, which was associated with the aggressive behavior of the benign tumor.

The experimental cell line HMOsisEC10 was developed from ovarian endometriotic epithelial cells without any evidence of cancer. Genome-wide association studies have revealed that $K R A S$ and PIK3CA mutations with a high mutant allele frequency accounted for $38 \%$ and $29 \%$ of the endometriotic epithelium sample mutations, respectively [14]. To confirm the presence of any type of somatic mutation, we subjected the developed cell line to whole-exome sequencing analysis, which revealed no somatic or germline mutations (Table S2). Consistent with a previous report, we confirmed that the established HMOsisEC10 cell line was isolated from the portion of an ovarian cyst with no somatic mutations. Subsequently, we established two new cell lines through transfection of KRAS and PIK3CA, which are frequently mutated genes in adverse conditions and are more relevant to carcinogenic behavior.

One study has shown that driver mutations in KRAS and PIK3CA may be both the reason and result of fibrogenesis, which may increase the risk of malignant transformation from benign endometriosis [30]. The KRAS gene is one of the major mutated isoforms of RAS, which encodes a signaling protein that can be activated by a variety of extracellular responses and relay the signal to the downstream RAS/MAPK signaling pathways, and is associated with all forms of cancerous phenotypes, such as increased cell growth, invasion, and migration [16,31,32]. Mutations in the PIK3CA gene are relevant in the PI3K/AKT signaling pathway, which is involved in tumors of the brain, colorectal, breast, and other tumor types, and is associated with cell proliferation, invasion, and metastasis [33]. Previous reports found that a reduced concentration of serum in media $(0.5 \%)$ decreased the growth rate of wild-type cells compared to the mutated cells, which is consistent with the results of our study. The PIK3CA mutant cell line had a 6-8-fold increase in migratory and invasive abilities compared to the wild-type cell line [34]. PIK3CA uses ATP to phosphorylate phosphatidylinositol, and mutations in PIK3CA were the most frequent genetic alterations of the PI3K pathway, which confers its enhanced growth and survival potential in adverse conditions [35]. The dominant nature of activated KRAS mutations causes aggressiveness in pancreatic cancer, and $K R A S$ has a well-established role in cell proliferation, migration, and invasion [32,36-38]. The results of the present study and those of previous studies suggest that the immortalized PIK3CA and KRAS mutant cell lines exhibit a higher degree of cell proliferation, invasion, and migration compared to normal endometriotic epithelial cells. However, these changes were not sufficient to induce the development of cancer from endometriosis. In the present study, immortalized HMOsisEC10 cells with KRAS and PIK3CA mutations failed to develop any colonies during the soft agar assay, while the in vivo model showed insufficient metastatic properties. Case and cohort studies have shown that the risk of malignant transformation of endometriosis was $0.3-0.8 \%[39,40]$, which supports the theory that at least three sequential genetic mutations are required to convert a single normal cell into a malignant one [41]. The HMOsisEC10 KRAS and 
HMOsisEC10 PIK3CA mutant cell lines in our study were insufficient, despite having driver mutations and aggressive behavior, to induce cancer development [3].

By scrutinizing gene expression profiles in these cells, it was revealed that several genes were associated with their cancer-like behavior. In this study, we have established the involvement of LOX and PTX3 in KRAS and PIK3CA mutated endometriotic epithelial cell migration, invasion, and proliferation-the key steps of the metastatic cascade. LOX gene expression is well established as a biomarker of many carcinomas and is upregulated in endometriosis tissue samples collected from humans as well as in an animal model of the disease [42,43]. In the recent past, LOX isoforms were identified as factors in the epithelial-mesenchymal transition (EMT), an event by which cancer cells gain motility and invasive mesenchymal cell properties [43]. Invasive epithelial cell lines show higher levels of LOX expression, whereas PTX3 promotes human liver cell growth [44,45]. A previous study reported that LOX cooperates with SNAIL at the protein level to facilitate the EMT and, thus, increases the invasive ability of breast cancer cell lines [46]. Another study also claimed that the overexpression of LOX promotes the proliferation, migration, and invasion of gastric cancer cell lines as well as high grade serous ovarian carcinoma [47,48]. In addition, PTX3 has pleiotropic roles in different types of cancer, such as gastric cancer, breast cancer, glioma, and prostate cancer. In hepatocellular carcinoma, several tissue studies have shown that increased PTX3 boosted cell proliferation, invasion, and migration capacity [49]. Consistent with these findings, it was revealed through microarray data in our study that $L O X$ and PTX3 were mechanistically related to increased cell proliferation, invasion, and migration. Knockdown of LOX and PTX3 in different mutant cell lines led to a significant decrease in cell proliferation, migration, and invasion abilities. Silencing or inhibition of $L O X$ has been reported to suppress the migration, invasion, and growth ability of esophageal squamous cell carcinoma by downregulating PIK3 harboring a PIK3CA mutation [44]. Conversely, knockdown of PTX3 significantly decreased the metastatic potential of cervical cancer cells as well as the migration and invasion ability of invasive melanoma cells in vitro [49,50].

Current treatment strategies for endometriosis, including surgical removal and hormonal therapy, are often unsatisfactory. Surgical removal is a commonly used treatment for severe endometriosis, but extraction can be hazardous and painful, and some patients may have unapproachable or remote tumors. Without hormonal treatment, the tumor returns within 5 years in a relevant percentage of surgical cases [51]. In addition, some hormonal therapies can significantly reduce the level of circulating estrogen, which causes delayed conception [52].

PI3K/AKT signaling pathway was increased in ovarian endometriosis, resulting from the aberrations in the regulation of progesterone receptor (PR). These inadequate responses to progesterone receptor in endometriosis could be associated with endocrine therapy resistance. In addition, oxidative stress is also involved in progesterone resistance in endometriosis $[53,54]$.

Furthermore, low dose estrogen progestin and visanne are often contraindicated, as they are associated with a risk of thrombosis or lipid disorder. Therefore, LOX and PTX3 may be potential therapeutic targets for aggressive endometriosis. Liquid biopsies of circulating tumor DNA (ctDNA) is a more accurate non-invasive diagnostic and monitoring tool for detecting tumor-specific mutations. Examination of cfDNA load with KRAS and PIK3CA mutation allows for the prediction of the abnormalities at an early stage, which can improve treatment outcomes. Silencing LOX and PTX3 expression using small molecules is a potential treatment strategy for reducing cell migration, invasion, and proliferation, especially in deep infiltrating endometriosis with KRAS and PIK3CA mutations.

\section{Materials and Methods}

\subsection{Ethical Approval}

This study was approved by the institutional ethics review board of Shimane Medical University, Izumo, Shimane, Japan (IRB No. 20070305-1 and No. 20070305-2, 5 March 2007). 


\subsection{Isolation and Purification of the Tissue Samples}

Human endometriotic tissue samples were obtained from ovarian endometriotic cysts collected from three different patients. Stromal cells were identified in one sample, and hence, it was discarded. Immortalized endometriotic epithelial cells were generated successfully from one of the remaining two samples with a success rate of $33 \%$. This immortalized endometriotic epithelial cell line was used in our study. The 48-year-old patient from whom endometriotic epithelial cells were collected successfully underwent a laparoscopic ovarian cystectomy as treatment for ovarian endometriosis. Briefly, the tissue samples were gently but thoroughly washed with sterile phosphate-buffered saline (PBS) to remove blood contamination. Next, the samples were dissected into small pieces $\left(1-2 \mathrm{~mm}^{3}\right)$ using sterile scissors and digested with collagenase type 3 (Washington Biochemical Corp. Lakewood, NJ, USA) in a shaking water bath at $37^{\circ} \mathrm{C}$ for $60 \mathrm{~min}$. To separate the epithelial glands from the stromal cells and debris, serial filtration through narrow gauge sieves was performed, whereby debris was removed using 100-micrometer aperture sieves, and epithelial glands were retained on 40-micrometer sieves. Individual glands were visualized under a microscope, collected into a micro centrifuge tube, and cultured in 24-well dishes for subsequent gene transfection using viral vectors. The patient included in this study provided written informed consent for the use of her clinical and pathological specimens.

\subsection{Vector Construction and Cell Transfection}

To generate immortalized cells, previously collected normal endometriotic cells were transduced with $h T E R T$, cyclin D1, and mutant CDK4 (CDK4 $4^{\mathrm{R} 24 \mathrm{C}}$ : an inhibitor-resistant form of CDK4) via lentivirus-mediated gene transfer using the Gateway system that has been described previously $[55,56]$. The construction of the recombinant lentiviruses with the help of the vesicular stomatitis virus $G$ glycoprotein has also been described previously [57]. cDNAs encoding mutant KRAS $\left(K R A S^{\mathrm{v} 12}\right)$ and PIK3CA were gifted to us by Dr. Goto (Aichi Cancer Research Institute, Nagoya, Japan). KRAS and PIK3CA mutant-overexpressing cells were established by lentivirus vector infection of the human KRAS and PIK3CA expression vectors $\mathrm{pCMSCV-EM7bsd-KRAS}$ and $\mathrm{pCMSCV-EM7bsd-PIK3CA}$. The cell lines were named as HMOsisEC10, HMOsisEC10 KRAS mutant, and HMOsisEC10 PIK3CA mutant cell lines.

\subsection{Cell Lines and Cell Culture}

Immortalized human ovarian endometriotic epithelial cell lines HMOsisEC10, mutant HMOsisEC10 KRAS, and HMOsisEC10 PIK3CA were established from ovarian endometriotic epithelial cells. All cell lines were grown in F-medium supplemented with 5\% fetal bovine serum (FBS; 10437-028, Gibco) and 1\% penicillin-streptomycin solution (P4333, Sigma-Aldrich) and maintained at $37^{\circ} \mathrm{C}$ in a humidified atmosphere with $5 \% \mathrm{CO}$. Images of the cell lines are presented in Figure S1.

\subsection{Western Blot Analysis}

Cell lysates were prepared by disrupting cell pellets in lysis buffer. Samples were prepared by adding LDS buffer and sample-reducing buffer, heated at $70^{\circ} \mathrm{C}$ for $10 \mathrm{~min}$, cooled on ice for $1 \mathrm{~min}$, and then centrifuged at $150 \mathrm{rpm}$ for $5 \mathrm{~min}$. Samples were then separated using SDS-PAGE (Invitrogen) and transferred onto PVDF membranes using Bio-Rad semi-dry trans blotters. Membranes were blocked with Licor blocking buffer (LICOR, Lincoln, NE, USA) for $1 \mathrm{~h}$ at room temperature and incubated with primary antibody (Table S3) diluted in LI-COR blocking buffer containing $0.1 \%$ Tween. The membrane was kept overnight on a shaker at $4{ }^{\circ} \mathrm{C}$. The membranes were washed four times for $5 \mathrm{~min}$ in TBST and then probed with goat anti-mouse or goat anti-rabbit secondary antisera labeled with IRDye 670 or $800 \mathrm{CW}$ diluted in LI-COR blocking buffer containing $0.1 \%$ Tween and $0.01 \%$ SDS was kept at room temperature on a shaker for $1 \mathrm{~h}$ covered with aluminum foil. The probe membranes were washed four times for $5 \mathrm{~min}$ in TBST, finally added to TBS, and imaged using a LI-COR Odyssey scanner. Boxes were manually drawn around each 
band of interest, and near-infrared fluorescent values for raw intensity, with intra-lane background subtracted, were obtained using Odyssey 3.0 analytical software (LI-COR).

\subsection{Immunocytochemistry}

Cells were cultured on a chamber slide (Sumilon cell desk LF1) in 24-well plates (50,000 cells per well). After $24 \mathrm{~h}$ of incubation, the plate was removed from the incubator and washed three times with PBS $(0.5 \mathrm{~mL})$. Cells were then fixed with $4 \%$ formalin for $10 \mathrm{~min}$ at room temperature and washed once with PBS. Samples were permeabilized with $0.1-0.5 \%$ Triton X-100 in PBS for $10 \mathrm{~min}$ and then washed with PBS three times (2 min, once; $5 \mathrm{~min}$, twice) on a shaker. Samples were incubated in 10\% normal goat serum for $1 \mathrm{~h}$ at room temperature. After blocking, the primary antibody (dilution 1:50) was added, incubated at $4{ }^{\circ} \mathrm{C}$ overnight, and then washed with PBS three times ( $2 \mathrm{~min}$, once; $5 \mathrm{~min}$, twice) on a shaker. The secondary antibody was added, incubated for $1 \mathrm{~h}$ covered with aluminum foil, and then washed with PBS three times ( $2 \mathrm{~min}$, once; $5 \mathrm{~min}$, twice) on a shaker. The cells were stained with DAPI, and the slide was sealed using nail polish enamel and viewed under a microscope.

\subsection{Short Tandem Repeat (STR) Analysis}

DNA extraction was performed on three passages of the HMOsisEC10 line using a DNeasy ${ }^{\circledR}$ Blood and Tissue Kit (QIAGEN, Hilden, Germany), following manufacturer protocol. Eight human STR loci (Table S5) were amplified in the ABI PRISM 310 genetic analyzer with $10 \mathrm{ng}$ of template DNA. Next, PCR was conducted in a BIO RAD T100 ${ }^{\mathrm{TM}}$ thermal cycler. Amplicons were visualized with $2 \%$ agarose gel electrophoresis and quantified using a spectrophotometer (NanoDrop 2000; Thermo Fisher Scientific, Waltham, MA, USA) to ensure accuracy and concentration uniformity. Amplicon aliquots $(1 \mu \mathrm{L})$ were placed in $0.5 \mathrm{~mL}$ sample tubes with $10 \mu \mathrm{L}$ deionized formamide and $0.5 \mu \mathrm{L}$ size-standard Gene Scan ${ }^{\mathrm{TM}} 500$ (Applied Biosystems). They were denatured at $95^{\circ} \mathrm{C}$ for $5 \mathrm{~min}$, instantly cooled on ice, and subjected to another electrophoresis in an ABI PRISM 310 genetic analyzer. Data were analyzed with ABI Genemapper v4.1 (Applied Biosystems).

\subsection{Simulated Wound Healing Assay to Assess Cell Motility}

Cells were seeded onto 6-well plates at a density of $1 \times 10^{6}$ cells per well and grown to a confluent monolayer. An acellular area was created by scraping the cell surface using a 200-microliter pipette tip (time 0 ). Non-attached cells were removed by gentle washes using the culture medium. The rate of wound closure was measured by monitoring the wound healing process for $24 \mathrm{~h}$. The cells that migrated to the wound area were counted $24 \mathrm{~h}$ after scraping. The individual cells in the monolayer defect were quantified as an average from multiple fields (at least five) at $200 \times$ magnification.

\subsection{Matrigel Invasion Assay}

The invasion assay was performed using a Corning Bio Coat Matrigel Invasion Chamber (Discovery Labware Inc., Bedford, MA, USA) with an 8-micron pore size. The chamber was removed from the refrigerator and $500 \mu \mathrm{L}$ of serum-free medium was added to the upper chamber along with the bottom chamber. The chambers were kept in a humidified tissue culture incubator at $37^{\circ} \mathrm{C}$ with $5 \% \mathrm{CO}_{2}$ for $1-2 \mathrm{~h}$. The serum-free medium was carefully removed from both the upper and bottom chambers. Cells were seeded at a density of $25,000 / 350 \mu \mathrm{L}$ in serum-free medium into the upper chamber. The lower compartment contained $900 \mu \mathrm{L}$ of F-medium containing $20 \%$ FBS as a chemoattractant. After $24 \mathrm{~h}$ of incubation at $37{ }^{\circ} \mathrm{C}$ under $5 \% \mathrm{CO}_{2}$, the chambers were removed from the incubator; the medium was removed from both the chambers followed by washing twice with sterile PBS and the addition of 3.7\% paraformaldehyde to both the upper and lower chambers for $2 \mathrm{~min}$. Subsequently, the wells were washed twice with PBS, and methanol was added to both the upper and lower chambers for $20 \mathrm{~min}$. After treatment with methanol, the wells were washed twice with PBS, and 5\% Giemsa stain was added to both the upper and lower 
chambers for $15 \mathrm{~min}$. Subsequently, the wells were washed twice with PBS followed by careful removal of the uninvaded cells with a cotton swab. Cells migrating through the membrane and cells invading the Matrigel were counted in 16 non-overlapping $200 \times$ fields under a light microscope.

\subsection{Cell Proliferation Assay}

Cells were seeded in a 96-well plate at a density of 3000 cells per well. Cell number was determined indirectly using an MTT assay [58]. The data were calculated as the mean \pm standard deviation (SD) of triplicate replications.

\subsection{Anchorage Independent Assay}

A total of 10,000 cells were seeded into 24-well plates containing a top layer of $0.33 \%$ noble agar in $2 \times$ DMEM supplemented with $5 \%$ FBS and a bottom layer of $0.5 \%$ base agar in $2 \times$ DMEM supplemented with 5\% FBS. After solidification of the gel, each well was covered with $1 \mathrm{~mL}$ of the culture medium and incubated at $37^{\circ} \mathrm{C}$. Colonies larger than $0.05 \mathrm{~mm}$ in diameter were counted after incubation for 2 weeks.

\subsection{Nude Mice Xenograft}

We injected each cell line $\left(2.5 \times 10^{7}\right.$ cells $\left./ \mathrm{mL}\right)$ into the subcutaneous tissues of 4-weekold athymic BLAB/c nu/nu mice (Charles River Japan INC., Kanagawa, Japan). Four mice were used for each experimental group. Tumor growth was monitored weekly for two months or until the mice became moribund. All animal experiments were performed in accordance with the regulations of the institutional ethical commission.

\subsection{Whole-Exome Sequencing}

Whole-exome sequencing was performed on the HMOsisEC10 cell line to determine the presence of any protein-coding mutations; the genome sequencing methods used have been previously described [59]. Briefly, quality control was assessed by generating a DNA integrity number using the Agilent 2000 TapeStation (Agilent Technologies, Santa Clara, CA, USA) prior to targeted amplicon whole-exome sequencing with the Illumina MiSeq sequencing platform (Illumina, San Diego, CA, USA). The lowest quality of DNA had a DIN score over 3.1, whereas the lowest DNA concentration was $50 \mathrm{ng}$. The sequencing data were analyzed using the GenomeJack bioinformatics pipeline (Mitsubishi Space Software, Tokyo, Japan) through various steps, including sequence alignment, variant calling, variant filtering, variant annotation, and variant prioritization to ensure accurate reporting of analytic sensitivity and specificity. We identified no cancer-specific alterations in the somatic genes, including single-nucleotide variations, insertions/deletions, and gene copynumber alterations. These results were used to determine the tumor mutational burden.

\subsection{Microarray Analysis}

Microarray analysis was performed at Takara Bio Incorporation (Tokyo, Japan) using an Agilent Sureprint G3 Human GE $8 \times 60 \mathrm{~K}$ microarray (Agilent Technologies, Palo Alto, CA, USA) containing 42,545 probe sets, according to the manufacturer's protocol. Briefly, RNA for cDNA microarray analysis was purified using RNeasy column purification (QIAGEN). Accuracy and concentration uniformity were confirmed using a Nano Drop ND-2000 spectrophotometer. Total RNA was labeled, amplified, hybridized, and scanned using the standard Agilent protocol. HMOsisEC10, HMOsisEC10 KRAS, and HMOsisEC10 PIK3CA samples were run on different ID columns including Agilent probes. Raw data were analyzed in feature extraction software (Agilent Technologies) using default parameters to obtain detrended processed signal intensities. The signal intensity data were normalized by the global scaling method. Duplicated probes on the array were treated independently during normalization and statistical analyses. To avoid extreme fold-change artifacts, negative or low-intensity signals less than 10 were corrected to 10 . The optimal selected gene probes were used to score the correlation of all muted cell samples with the KRAS 
and PI3KCA gene signature. Depending on whether the gene signature score exceeded a predefined threshold, a sample was classified as an activated oncogenic or wild-type-like.

\subsection{5. siRNA Transfection}

RNA interference and siRNA preparation were performed over $48 \mathrm{~h}$. Effects of siRNA (LOX and PTX3) (Santa Cruz Biotechnology) were compared with those of a control siRNA and untreated cells. Cells were plated into 6-well plates for the migration assay and allowed to grow to a confluent monolayer before transfection. Transfection methods were as follows: mixing Opti-MEM ${ }^{\circledR}$ medium $150 \mu \mathrm{L}$ and Lipofectamine ${ }^{\circledR}$ RANIMAX $9 \mu \mathrm{L}$, and mixing Opti-MEM ${ }^{\circledR}$ medium $150 \mu \mathrm{L}$ and $6 \mu \mathrm{L}(20 \mathrm{~nm})$ siRNA (LOX and/or PTX3). Then, diluent siRNA was added to the diluent Lipofectamine ${ }^{\circledR}$ RANIMAX reagent $(1: 1)$ and incubated for $5 \mathrm{~min}$ at room temperature. We subsequently added $250 \mu \mathrm{L}$ of the siRNA mix into each well. After $48 \mathrm{~h}$, scratches were made using a 200-microliter pipette. For the invasion assay, 25,000 cells were plated into 24-well plates mixing Opti-MEM ${ }^{\circledR}$ medium $50 \mu \mathrm{L}$ and Lipofectamine ${ }^{\circledR}$ RANIMAX $3 \mu \mathrm{L}$, and $50 \mu \mathrm{L}$ of Opti-MEM ${ }^{\circledR}$ medium and $2 \mu \mathrm{L}$ (20 nm) siRNA (LOX and/or PTX3), followed by incubation for $5 \mathrm{~min}$ at room temperature. Next, $50 \mu \mathrm{L}$ of siRNA mix was added into each well. After $48 \mathrm{~h}$ of transfection, cells were transferred onto a Matrigel-coated upper chamber, and $20 \%$ chemoattractant was added to the bottom chamber. After $24 \mathrm{~h}$, we checked for cell invasion. For the proliferation assay, the cells were transfected with siRNA (LOX and/or PTX3) in 96-well plates at $20 \mathrm{nM}$ and the results were obtained on days 0,2 , and 3 . To avoid off-target effects, different siRNAs (LOX and PTX3; Ambion Life Technologies) were also used to perform the migration, invasion, and proliferation assays. The sequences of the siRNAs (LOX and PTX3) are listed in Table S4.

\subsection{Reverse Transcriptase Polymerase Chain Reaction (RT-PCR)}

The cell pellet was homogenized using QIAGEN buffer RLT (QIAGEN GmbH, QIAGEN, Hilden, Germany). Total RNA was isolated using a standard protocol (Qiagen N.V) according to the manufacturer's instructions. The RNA quantity was measured by spectrophotometry using a NanoDrop ND-1000 (NanoDrop Technologies, Wilmington, DE, USA). The reverse transcriptase polymerase chain reaction (RT-PCR) was performed using the Applied Biosystems SYBR Green master mix kit, purchased from Thermo Fisher Scientific, Inc. The primer sequences used for RT-PCR are included in Table 1. Standard cycling conditions were used: $95^{\circ} \mathrm{C}$ for $30 \mathrm{~s}, 95^{\circ} \mathrm{C}$ for $5 \mathrm{~s}, 60{ }^{\circ} \mathrm{C}$ for $30 \mathrm{~s}$ followed by 40 cycles at $95^{\circ} \mathrm{C}$ for $15 \mathrm{~s}$, and $60^{\circ} \mathrm{C}$ for $30 \mathrm{~s}$, then $95^{\circ} \mathrm{C}$ for $15 \mathrm{~s}$. Gene expression levels were standardized to the levels of GAPDH using the $2^{-\triangle \Delta C t}$ method. The experiment was independently repeated at least three times.

Table 1. List of RT-PCR primer sequences for validation of microarray data.

\begin{tabular}{ccc}
\hline Name of Primer & Type & Sequence $\left(\mathbf{5}^{\prime}-\mathbf{3}^{\prime}\right)$ \\
\hline \multirow{2}{*}{$L O X$} & $\begin{array}{c}\text { Forward } \\
\text { Reverse }\end{array}$ & TGCCAGTGGATTGATATTAC \\
& TACGGTGAAATTGTGCAGCC \\
\hline \multirow{2}{*}{$P T X 3$} & Forward & GCATCTCCTTGCGATTCTGTT \\
& Reverse & CATTCCGAGTGCTCCTGACC \\
\hline \multirow{2}{*}{ GAPDH } & Forward & ACGGGAAGCTTGTCATCAAT \\
& Reverse & TGGACTCCACGACGTACTCA \\
\hline
\end{tabular}

\section{Conclusions}

In summary, by using the immortalized human ovarian endometriotic cell line HMOsisEC10, we have established two new mutant cell lines, HMOsisEC10 KRAS and HMOsisEC10 PIK3CA, through in vitro vector construction and cell transfection. Mutant cells exhibited a significant increase in proliferation, migration, and invasion potential. Microarray gene-expression analysis revealed several genes that demonstrated correlations 
with KRAS or PIK3CA invasion-specific gene signatures, which played essential roles in activating the endometriosis progression pathways. We showed that LOX and PTX3 were the main downstream targets of the KRAS and PIK3CA mutant endometriotic epithelial cells. Thus, we speculate that the inhibition of LOX and PTX3 could provide a better treatment for ovarian endometriosis. Furthermore, this experimental model may be the key to attaining a better understanding of the functional and molecular pathogenesis of endometriosis and might provide a novel therapeutic target to reduce the further incidence of endometriosis.

Supplementary Materials: The following are available online at https:/ /www.mdpi.com/article/10 .3390/cancers13133174/s1, Figure S1: Morphological characteristics of immortalized endometriotic epithelial cells: HMOsisEC10, HMOsisEC10 KRAS, and HMOsisEC10 PIK3CA. Figure S2: Western blot (left panel) and immunocytochemical analyses (right panel) of pan-cytokeratin expression in immortalized HMOsis EC10 (WT) cells. Figure S3: Western blot analysis of pan-cytokeratin, panAKT, phospho-AKT, pan-MAPK and phospho-MAPK expression in different transfectants. (A) Immortalized endometriotic epithelial cells (HMOsisEC10), (B) HMOsis EC10 KRAS cells, and (C) HMOsisEC10 PIK3CA cells. Figure S4: Short tandem repeat (STR) analysis of HMOsisEC10 immortal cells. Comparison of genotyping results in adjacent HMOsisEC10 cells at passages 2, 13, and 22 with eight STR loci (TPOX, CSF1P0, VWA, FGA, D3S1359, D18S51, D8S315, and SE33). All eight loci were amplified and demonstrated to have identical genotypes, indicating that there was no crosscontamination between the different cell passages. Figure S5: Anchorage independent assay. No colony formation was observed in the mutant cell lines HMOsisEC10 KRAS (left) and HMOsisEC10 PIK3CA (middle). Image was acquired 30 days following passage. The SKOV3 cell line (positive control) showed colony formation after 30 days of passage on the agar medium (right). Figure S6: In vivo inoculation of HMOsisEC10 KRAS (left) and HMOsisEC10 PIK3CA mutant cells (middle) into mice; the photograph was captured 60 days after inoculation. No tumor development was observed in the mice inoculated with the mutant cell lines. However, tumor development was observed in the mouse inoculated with the SKOV3 cell line (right) as a positive control. Figure S7: In the exome sequencing result, copy number alteration (CNA) plot shows DNA from both parental lines (maternal and paternal) has no significant variation/mutation present. Figure S8: Validation of microarray data using RT-PCR. The mean fold changes in the mRNA expression level of LOX and PTX3 are shown on the $y$-axis. For both LOX and PTX3 mRNAs, the microarray and RT-PCR results are consistent with those in HMOsisEc10 KRAS and HMOsisEC10 PIK3CA mutant cell lines. Figure S9: Cell migration assay. Migration abilities of mutant cell lines (HMOsisEC10 KRAS and HMOsisEC10 PIK3CA) measured using a scratch wound healing assay after knockdown with $L O X(A 1, A 2)$ and PTX3 siRNA (B1, B2). The numbers of migrated cells were significantly lower in siRNA-treated cells compared to the control siRNA and untreated cells. Matrigel invasion assay; siRNA knockdown of LOX (C1, C2) and PTX3 (D1, D2) showed a significantly lower invasion capacity than control siRNA and untreated cells. Cell proliferation assay. Treatment with LOX (E1, E2) and PTX3 siRNA (F1, F2) significantly reduced cell proliferation ability relative to the control siRNA and untreated cells. ${ }^{* *} p<0.01$ and ${ }^{*} p<0.05$. The error bars indicate standard deviation. Table S1: Description of primary antibodies. Table S2: Whole-exome sequencing result of HMOsisEC10 cells. Table S3: Gene expression level of RhoA, TNF- $\alpha$, and SRF. Table S4: Sequences of siRNA LOX and siRNA PTX3. Table S5: Primers for STR amplicon and chromosomal location.

Author Contributions: M.M.H. Investigation, formal analysis, visualization, writing original draft and K.N. conceptualization, methodology, supervision, validation and review and editing original draft K.S., S.R., M.I., T.I., H.Y., K.K., S.S. carried out formal analysis and critical revision of manuscript. Data curation and resources of sample was done by K.I. Identify and conformation of pathological sample was done by N.I., T.K. assist to develop immortalized cell line. M.M.H. and K.S. carried out the statistical analyses and organizing data. K.N. participated in the design of the study. S.K. funding acquisition, project administration, supervision conceived the study, participated in its design and coordination. All authors have read and agreed to the published version of the manuscript.

Funding: This research was supported by JSPS KAKENHI, grant numbers $18 \mathrm{~K} 09229$ and $18 \mathrm{~K} 09291$. 
Institutional Review Board Statement: This study was approved by the institutional ethics review board of Shimane Medical University, Izumo, Shimane, Japan (IRB No. 20070305-1 and No. 200703052, 5 March 2007).

Informed Consent Statement: The patient included in this study provided written informed consent for the use of her clinical and pathological specimens.

Data Availability Statement: The data that support the finding of this study are available from the corresponding author upon responsible request.

Acknowledgments: We thank all members of the Department of Obstetrics and Gynecology Research team for their advice, suggestions and valuable discussions during the preparation of this manuscript.

Conflicts of Interest: The authors declare no potential conflicts of interest.

$\begin{array}{ll}\text { Abbreviations } \\ \text { KRAS: } & \text { Kristen Rat Sarcoma } \\ \text { PIK3CA } & \text { Phosphatidylinositol-4,5-Bisphosphate 3-Kinase Catalytic Subunit Alpha } \\ \text { LOX } & \text { lysyl oxidase } \\ \text { PTX3 } & \text { Pentraxin3 } \\ \text { RT-PCR } & \text { Reverse Transcriptase Polymerase Chain Reaction } \\ \text { RhoA } & \text { Ras homolog family member A, } \\ \text { TNF- } \alpha & \text { Tumor Necrotic Factor- } \alpha \\ \text { SRF } & \text { Serum Response Factor } \\ \text { hTERT } & \text { humans Telomerase Reverse Transcriptase } \\ \text { CDK4 } & \text { Cyclin Dependent Kinase } 4 \\ \text { STR } & \text { Short Tandem Repeat } \\ \text { SiRNA } & \text { small interfering RNA }\end{array}$

\section{References}

1. Olive, D.L.; Pritts, E.A. Treatment of endometriosis. N. Engl. J. Med. 2001, 345, 266-275. [CrossRef] [PubMed]

2. Giudice, L.C.; Kao, L.C. Endometriosis. Lancet 2004, 364, 1789-1799. [CrossRef]

3. Anglesio, M.S.; Papadopoulos, N.; Ayhan, A.; Nazeran, T.M.; Noë, M.; Horlings, H.M.; Lum, A.; Jones, S.; Senz, J.; Seckin, T.; et al. Cancer associated mutation in Endometriosis without cancer. N. Engl. J. Med. 2017, 376, 1835-1848. [CrossRef] [PubMed]

4. Simoens, S.; Dunselman, G.; Dirksen, C.; Hummelshoj, L.; Bokor, A.; Brandes, I.; Brodszky, V.; Canis, M.; Colombo, G.L.; DeLeire, T.; et al. The burden of endometriosis: Costs and quality of life of women with endometriosis and treated in referral centers. Hum. Reprod. 2012, 27, 1292-1299. [CrossRef] [PubMed]

5. Nnoaham, K.E.; Hummelshoj, L.; Webster, P.; d'Hooghe, T.; Nardone, F.C.; Jenkinson, C.; Phil, D.; Kennedy, S.H.; Zondervan, K.T. Impact of endometriosis on quality of life and work productivity: A multicenter study across ten countries. Fertil Steril. 2011, 96, 366-373. [CrossRef] [PubMed]

6. Cho, Y.J.; Lee, S.H.; Park, J.W.; Han, M.; Park, M.J.; Han, S.J. Dysfunctional signaling underlying endometriosis: Current state of knowledge. J. Mol. Endocrinol. 2018, 60, 97-113. [CrossRef] [PubMed]

7. Sampson, J.A. Metastatic or Embolic Endometriosis, due to the Menstrual Dissemination of Endometrial Tissue into the Venous Circulation. Am. J. Pathol. 1927, 3, 93-110.

8. Vercellini, P.; Viganò, P.; Somigliana, E.; Fedele, L. Endometriosis: Pathogenesis and treatment. Nat. Rev. Endocrinol. 2014, 10, 261-275. [CrossRef] [PubMed]

9. Johnson, N.P.; Hummelshoj, L.; Adamson, G.D.; Keckstein, J.; Taylor, H.S.; Abrao, M.S.; Bush, D.; Kiesel, L.; Tamimi, R.; SharpeTimms, K.L.; et al. World Endometriosis Society consensus on the classification of endometriosis. Hum. Reprod. 2017, 32, 315-324. [CrossRef] [PubMed]

10. Sato, N.; Tsunoda, H.; Nishida, M.; Morishita, Y.; Takimoto, Y.; Kubo, T.; Noguchi, M. Loss of heterozygosity on $10 q 23.3$ and mutation of the tumor suppressor gene PTEN in benign endometrial cyst of the ovary: Possible sequence progression from benign endometrial cyst to endometrioid carcinoma and clear cell carcinoma of the ovary. Cancer Res. 2000, 60, 7052-7056. [PubMed]

11. Wiegand, K.C.; Shah, S.P.; Al-Agha, O.M.; Zhao, Y.; Tse, K.; Zeng, T.; Senz, J.; McConechy, M.K.; Anglesio, M.S.; Kalloger, S.E.; et al. ARID1A Mutation in endometriosis- Associated Ovarian Carcinoma. N. Engl. J. Med. 2010, 363, 1532-1543. [CrossRef] [PubMed]

12. Vestergaard, A.L.; Thorup, K.; Knudsen, U.B.; Munk, T.; Rosbach, H.; Poulsen, J.B.; Guldberg, P.; Martensen, P.M. Oncogenic events associated with endometrial and ovarian cancer are rare endometriosis. Mol. Hum. Reprod. 2011, 17, 758-761. [CrossRef] [PubMed] 
13. Murakami, K.; Kotani, Y.; Nakai, H.; Matsumura, N. Endometriosis-Associated Ovarian Cancer: The Origin and Targeted Therapy. Cancers 2020, 12, 1676. [CrossRef] [PubMed]

14. Jimbo, H.; Yoshikawa, H.; Onda, T.; Yasugi, T.; Sakamoto, A.; Taketani, Y. Prevalence of ovarian endometriosis in epithelial ovarian cancer. Int. J. Gynaecol. Obstet. 1997, 59, 245-250. [CrossRef]

15. Wei, J.J.; William, J.; Bulun, S. Endometriosis and ovarian cancer: A review of clinical, pathologic, and molecular aspects. Int. J. Gynecol. Pathol. 2011, 30, 553-568. [CrossRef] [PubMed]

16. Suda, K.; Nakaoka, H.; Yoshihara, K.; Ishiguro, T.; Tamura, R.; Mori, Y.; Yamawaki, K.; Adachi, S.; Takahashi, T.; Kase, H.; et al. Clonal expansion and diversification of cancer associated mutation in endometriosis and normal endometrium. Cell Rep. 2018, 24, 1777-1789. [CrossRef]

17. Suda, K.; Nakaoka, H.; Yoshihara, K.; Ishiguro, T.; Adachi, S.; Kase, H.; Motoyama, T.; Inoue, I.; Enomoto, T. Different mutation profiles between epithelium and stroma in endometriosis and normal endometrium. Hum. Reprod. 2019, 34, 1899-1905. [CrossRef] [PubMed]

18. Suda, K.; Cruz Diaz, L.A.; Yoshihara, K.; Nakaoka, H.; Yachida, N.; Motoyama, T.; Inoue, I.; Enomoto, T. Clonal lineage from normal endometrium to ovarian clear cell carcinoma through ovarian endometriosis. Cancer Sci. 2020, 111, 3000-3009. [CrossRef] [PubMed]

19. Lac, V.; Verhoef, L.; Aguirre-Hernandez, R.; Nazeran, T.M.; Tessier-Cloutier, B.; Praetorius, T.; Orr, N.L.; Noga, H.; Lum, A.; Khattra, J.; et al. Iatrogenic endometriosis harbors somatic cancer-driver mutations. Hum. Reprod. 2019, 34, 69-78. [CrossRef]

20. Moore, L.; Leongamornlert, D.; Coorens, T.H.H.; Sanders, M.A.; Ellis, P.; Dentro, S.C.; Dawson, K.J.; Butler, T.; Rahbari, R.; Mitchell, T.J.; et al. The mutational landscape of normal human endometrial epithelium. Nature 2020, 580, 640-646. [CrossRef] [PubMed]

21. Inoue, S.; Hirota, Y.; Ueno, T.; Fukui, Y.; Yoshida, E.; Hayashi, T.; Kojima, S.; Takeyama, R.; Hashimoto, T.; Kiyono, T.; et al. Uterine adenomyosis is an oligoclonal disorder associated with KRAS mutations. Nat. Commun. 2019, 10, 5785. [CrossRef] [PubMed]

22. Kobayashi, H. Somatic driver mutations in endometriosis as possible regulators of fibrogenesis (Review). World Acad. Sci. J. 2019, 12, 105-112. [CrossRef]

23. Shiomi, K.; Kiyono, T.; Okamura, K.; Uezumi, M.; Goto, Y.; Yasumoto, S.; Shimizu, S.; Hashimoto, N. CDK4 and Cyclin D1 Allow Human Myogenic Cells to Recapture Growth Property Without Compromising Differentiation Potential. Gene Ther. 2011, 18, 857-866. [CrossRef]

24. Benvenuti, S.; Frattini, M.; Arena, S.; Zanon, C.; Cappelletti, V.; Coradini, D.; Daidone, M.G.; Pilotti, S.; Pierotti, M.A.; Bardelli, A. PIK3CA cancer mutations display gender and tissue specificity patterns. Hum Mutat. 2008, 29, 284-288. [CrossRef] [PubMed]

25. Kwon, M.C.; Berns, A. Mouse models for lung cancer. Mol. Onchol. 2013, 7, 165-177. [CrossRef]

26. Gutierrez, E.; Cahatol, I.; Bailey, C.A.R.; Lafargue, A.; Zhang, N.; Song, Y.; Tian, H.; Zhang, Y.; Chan, R.; Gu, K.; et al. Regulation of RhoB Gene Expression during Tumorigenesis and Aging Process and Its Potential Applications in These Processes. Cancers 2019, 11, 818. [CrossRef]

27. Ridley, A.J. RhoA, RhoB and RhoC have different roles in cancer cell migration. J. Microsc. 2013, 251, 242-249. [CrossRef]

28. Mong, P.Y.; Petrulio, C.; Kaufman, H.L.; Wang, Q. Activation of Rho kinase by TNF-alpha is required for JNK activation in human pulmonary microvascular endothelial cells. J. Immunol. 2008, 180, 550-558. [CrossRef]

29. Berenjeno, I.M.; Núñez, F.; Bustelo, X.R. Transcriptomal profiling of the cellular transformation induced by Rho subfamily GTPases. Oncogene 2007, 26, 4295-4305. [CrossRef]

30. Guo, S.W. Cancer driver mutations in endometriosis: Variations on the major theme of fibrogenesis. Reprod. Med. Biol. 2018, 16, 369-397. [CrossRef]

31. Otsuka, J.; Okuda, T.; Sekizawa, A.; Amemiya, S.; Saito, H.; Okai, T.; Kushima, M.; Tachikawa, T. K-ras mutation may promote carcinogenesis of endometriosis leading to ovarian clear cell carcinoma. Med. Electron. Microsc. 2004, 37, 188-192. [CrossRef]

32. Rachagani, S.; Senapati, S.; Chakraborty, S.; Ponnusamy, M.P.; Kumar, S.; Smith, L.M.; Jain, M.; Batra, S.K. Activated KrasG ${ }^{12}$ D is associated with invasion and metastasis of pancreatic cancer cells through inhibition of E-cadherin. Br. J. Cancer 2011, 104, 1038-1048. [CrossRef] [PubMed]

33. Yang, J.; Nie, J.; Ma, X.; Wei, Y.; Peng, Y.; Wei, X. Targeting PI3K in cancer: Mechanisms and advances in clinical trials. Mol. Cancer 2019, 18, 26. [CrossRef] [PubMed]

34. Samuels, Y.; Diaz, L.A., Jr.; Schmidt-Kittler, O.; Cummins, J.M.; Delong, L.; Cheong, I.; Rago, C.; Huso, D.L.; Lengauer, C.; Kinzler, K.W.; et al. Mutant PIK3CA promotes cell growth and invasion of human cancer cells. Cancer Cell. 2005, 7, 561-573. [CrossRef] [PubMed]

35. Hennessy, B.T.; Smith, D.L.; Ram, P.T.; Lu, Y.; Mills, G.B. Exploiting the PI3K/AKT pathway for cancer drug discovery. Nat. Rev. Drug Discov. 2005, 4, 988-1004. [CrossRef] [PubMed]

36. Wang, J.Y.; Lian, S.T.; Chen, Y.F.; Yang, Y.C.; Chen, L.T.; Lee, K.T.; Huang, T.J.; Lin, S.R. Unique K-ras Mutational Pattern in Pancreatic Adenocarcinoma from Taiwanese Patients. Cancer Lett. 2002, 180, 153-158. [CrossRef]

37. Hezel, A.F.; Kimmelman, A.C.; Stanger, B.Z.; Bardeesy, N.; Depinho, R.A. Genetics and Biology of Pancreatic Ductal Adenocarcinoma. Genes Dev. 2006, 20, 1218-1249. [CrossRef]

38. Tuveson, D.A.; Shaw, A.T.; Willis, N.A.; Silver, D.P.; Jackson, E.L.; Chang, S.; Mercer, K.L.; Grochow, R.; Hock, H.; Crowley, D.; et al. Endogenous Oncogenic K-ras(G12D) Stimulates Proliferation and Widespread Neoplastic and Developmental Defects. Cancer Cell. 2004, 5, 375-387. [CrossRef] 
39. Dawson, A.; Fernandez, M.L.; Anglesio, M.; Yong, P.J.; Carey, M.S. Endometriosis and endometriosis-associated cancers: New insights into the molecular mechanisms of ovarian cancer development. Ecancermedicalscience 2018, 12, 803. [CrossRef]

40. Heaps, J.M.; Nieberg, R.K.; Berek, J.S. Malignant neoplasms arising in endometriosis. Obstet Gynecol. 1990, 75, 1023-1028. [CrossRef]

41. Vogelstein, B.; Kinzler, K.W. The Path to Cancer -Three Strikes and You're Out. N. Engl. J. Med. 2015, 373, 1895-1908. [CrossRef] [PubMed]

42. Liu, Y.; Wang, G.; Liang, Z.; Mei, Z.; Wu, T.; Cui, A.; Liu, C.; Cui, L. Lysyl oxidase: A colorectal cancer biomarker of lung and hepatic metastasis. Thorac. Cancer 2018, 9, 785-793. [CrossRef]

43. Ruiz, L.A.; Báez-Vega, P.M.; Ruiz, A.; Peterse, D.P.; Monteiro, J.B.; Bracero, N.; Beauchamp, P.; Fazleabas, A.T.; Flores, I. Dysregulation of Lysyl Oxidase Expression in Lesions and Endometrium of Women with Endometriosis. Reprod. Sci. 2015, 22, 1496-1508. [CrossRef] [PubMed]

44. Kalikawe, R.; Baba, Y.; Nomoto, D.; Okadome, K.; Miyake, K.; Eto, K.; Hiyoshi, Y.; Nagai, Y.; Iwatsuki, M.; Ishimoto, T.; et al. Lysyl oxidase impacts disease outcomes and correlates with global DNA hypomethylation in esophageal cancer. Cancer Sci. 2019, 110, 3727-3737. [CrossRef]

45. Song, T.; Wang, C.; Guo, C.; Liu, Q.; Zheng, X. Pentraxin 3 overexpression accelerated tumor metastasis and indicated poor prognosis in hepatocellular carcinoma via driving epithelial-mesenchymal transition. J. Cancer 2018, 9, 2650-2658. [CrossRef]

46. Moon, H.J.; Finney, J.; Xu, L.; Moore, D.; Welch, D.R.; Mure, M. MCF-7 cells expressing nuclear associated lysyl oxidase-like 2 (LOXL2) exhibit an epithelial-to-mesenchymal transition (EMT) phenotype and are highly invasive in vitro. J. Biol. Chem. 2013, 288, 30000-30008. [CrossRef] [PubMed]

47. Yang, X.H.; Zhuang, M.K.; Xie, W.H.; Du, F.; Huang, Y.H.; Chen, Z.X.; Chen, F.L.; Wang, X.Z. 12-Lipoxygenase promotes epithelial-mesenchymal transition via the Wnt/ $\beta$-catenin signaling pathway in gastric cancer cells. Oncol. Targets Ther. 2019, 12, 5551-5561. [CrossRef] [PubMed]

48. De Donato, M.; Petrillo, M.; Martinelli, E.; Filippetti, F.; Zannoni, G.F.; Scambia, G.; Gallo, D. Uncovering the role of nuclear Lysyl oxidase (LOX) in advanced high grade serous ovarian cancer. Gynecol. Oncol. 2017, 146, 170-178. [CrossRef] [PubMed]

49. Rathore, M.; Girard, C.; Ohanna, M.; Tichet, M.; Ben Jouira, R.; Garcia, E.; Larbret, F.; Gesson, M.; Audebert, S.; Lacour, J.P.; et al. Cancer Cell-Derived Long Pentraxin 3 (PTX3) Promotes Melanoma Migration through a Toll-Like Receptor 4 (TLR4)/NF-kB Signaling Pathway. Oncogene 2019, 38, 5873-5889. [CrossRef]

50. Ying, T.H.; Lee, C.H.; Chiou, H.L.; Yang, S.F.; Lin, C.L.; Hung, C.H.; Tsai, J.P.; Hsieh, Y.H. Knockdown of Pentraxin 3 suppresses tumorigenicity and metastasis of human cervical cancer cells. Sci. Rep. 2016, 6, 29385. [CrossRef] [PubMed]

51. Vercellini, P.; Somigliana, E.; Viganò, P.; De Matteis, S.; Barbara, G.; Fedele, L. The effect of second-line surgery on reproductive performance of women with recurrent endometriosis: A systematic review. Acta Obstet. Gynecol. Scand. 2009, 88, $1074-1082$. [CrossRef] [PubMed]

52. Elnashar, A. Emerging treatment of endometriosis. Middle East Fertil. Soc. J. 2015, 20, 61-69. [CrossRef]

53. Lee, I.I.; Kim, J.J. Influence of AKT on progesterone action in endometrial diseases. Biol. Reprod. 2014, 91, 63. [CrossRef] [PubMed]

54. Reis, F.M.; Coutinho, L.M.; Vannuccini, S.; Batteux, F.; Chapron, C.; Petraglia, F. Progesterone receptor ligands for the treatment of endometriosis: The mechanisms behind therapeutic success and failure. Hum. Reprod. Update 2020, 26, 565-585. [CrossRef] [PubMed]

55. Bono, Y.; Kyo, S.; Takakura, M.; Maida, Y.; Mizumoto, Y.; Nakamura, M.; Nomura, K.; Kiyono, T.; Inoue, M. Creation of immortalized epithelial cells from ovarian endometrioma. Br. J. Cancer 2012, 106, 1205-1213. [CrossRef] [PubMed]

56. Wölfel, T.; Hauer, M.; Schneider, J.; Serrano, M.; Wölfel, C.; Klehmann-Hieb, E.; De Plaen, E.; Hankeln, T.; Meyer zum Büschenfelde, K.H.; Beach, D. A p16INK4a-insensitive CDK4 mutant targeted by cytolytic T lymphocytes in a human melanoma. Science 1995, 269, 1281-1284. [CrossRef]

57. Miyoshi, H.; Blömer, U.; Takahashi, M.; Gage, F.H.; Verma, I.M. Development of a Self-Inactivating Lentivirus Vector. J. Virol. 1998, 72, 8150-8157. [CrossRef]

58. Nakayama, K.; Miyazaki, K.; Kanzaki, A.; Fukumoto, M.; Takebayashi, Y. Expression and Cisplatin Sensitivity of CopperTransporting P-type Adenosine Triphosphates (ATP7B) in Human Solid Carcinoma Cell Lines. Oncol. Rep. 2001, 8, $1285-1287$. [PubMed]

59. Nakamura, K.; Aimono, E.; Tanishima, S.; Imai, M.; Nagatsuma, A.K.; Hayashi, H.; Yoshimura, Y.; Nakayama, K.; Kyo, S.; Nishihara, H. Intratumoral Genomic Heterogeneity May Hinder Precision Medicine Strategies in Patients with Serous Ovarian Carcinoma. Diagnostics 2020, 10, 200. [CrossRef] [PubMed] 